\title{
Hubungan Stres Kerja dengan Kelelahan Kerja Petani Karet di PTPN XII Kebun Renteng, Ajung-Jember
}

\section{(Correlation between Job Stress and Work Fatigue of Rubber Farmers In PTPN XII Renteng Gardens, Ajung-Jember)}

\author{
Sari Mulianingrum ${ }^{1}$, Erti Ikhtiarini Dewi ${ }^{2}$, Enggal Hadi Kurniyawan ${ }^{3}$ \\ Program Studi Ilmu Keperawatan Fakultas Keperawatan Universitas Jember \\ JI. Kalimantan No.37 Kampus Tegal Boto Jember \\ Telp/Fax: (0331) 32450 \\ e-mail: mulianingrumsari@gmail.com
}

\begin{abstract}
Rubber farmers often face heavy workload problems, cold weather and unsafe environmental conditions that cause job stress and work fatigue. The purpose of the study was to analyze the relationship between job stress and work fatigue of rubber farmers. The study design used observational analytic research with cross sectional approach and simple random sampling technique. There were 78 respondents. Data were collected using the job stress questionnaire and the Fatigue Severity Scale (FSS). Data analysis was performed by Spearman-rank Correlation test with a significance level of 0.05 . The results showed that from 78 people there were 73 people (92.6\%) experienced severe stress. And as many as 78 respondents (100\%) experienced high work fatigue. There was a significant relationship between job stress and work fatigue of rubber farmer in PTPN XII Renteng Gardens, Ajung-Jember ( $p$ value 0,000; $r=$ 0.538). A positive relationship meaning the higher of job stress the higher of work fatigue. Farmers were recommended to do relaxation therapy to prevent the work fatigue due to work stress.
\end{abstract}

Keywords: job stress, work fatigue, rubber farmer

\begin{abstract}
Abstrak
Petani karet sering menghadapi masalah beban kerja yang berat, cuaca dingin dan kondisi lingkungan yang tidak aman yang menyebabkan stres kerja dan kelelahan kerja. Tujuan dari penelitian ini adalah untuk menganalisis hubungan antara stres kerja dengan kelelahan kerja petani karet. Desain penelitian menggunakan penelitian analitik observasional dengan pendekatan cross sectional dan menggunakan teknik sampling simple random sampling yang menghasilkan 78 responden. Pengumpulan data menggunakan kuesioner stres kerja dan Fatigue Severity Scale (FSS). Analisis data dilakukan dengan uji Korelasi Spearman-rank dengan tingkat signifikansi 0,05 dan ada hubungan antara stres kerja dan kelelahan kerja. Hasil penelitian menunjukkan bahwa dari 78 orang terdapat 73 orang (92,6\%) yang berarti petani mengalami stres tinggi. Dan sebanyak 78 responden (100\%) mengalami kelelahan kerja yang tinggi. Ada hubungan yang signifikan antara stres kerja dan kelelahan kerja petani karet di PTPN XII Taman Renteng, Kabupaten Ajung, Kabupaten Jember ( $p$ value 0,000; $r=$ 0,538), memiliki hubungan positif atau semakin tinggi stres kerja semakin tinggi kelelahan kerja. Petani dapat melakukan terapi relaksasi untuk mencegah terjadinya stres kerja sehingga tidak menyebabkan kelelahan kerja.
\end{abstract}

Kata Kunci : stres kerja, kelelahan kerja, petani karet 
Mulianigrum, et al, Hubungan Stres Kerja Dengan Kelelahan Kerja Petani Karet di PTPN XII Renteng....

\section{Pendahuluan}

Petani karet adalah seseorang yang membudidayakan tanaman karet dengan harapan untuk memperoleh hasil dari tanaman untuk memenuhi kebutuhan sehari-hari [1]. Masalah yang sering dihadapi petani adalah banyaknyatuntutan permintaan tentangproduk yang mempengaruhi produktivitas kerja petani, beban kerja petani karet yang dirasa berat cuaca yang tidak menentu dan kondisi lingkungan kerja yangkurang memada. Beberapa masalah tersebutdapat memicu timbulnya

stres kerja. Stres merupakan suatu kondisi berupa tuntutan non spesifik dimana seorang individu diharuskan untuk berespon dan melakukan suatu tindakan [2]. Menurut Mangkunegara (2005) stres kerja adalah perasaan yang menekan atau merasa tertekan yang dialami pekerja dalam menghadapi pekerjaan [3]. Menurut survey yang dilakukan pada tahun 2012, sebanyak $64 \%$ pekerja di Indonesia mengalami peningkatan stres dibandingkan tahun 2011 [4]. Seseorang yang mengalami stres biasanya megalami respon fisik seperti hilangnya nafsu makan, menurunnya titik fokus, sakit kepala, dan lain-lain. Adapun respon psikologis yaitu timbulnya rasa cemas, penurunan motivasi, tidak percaya diri, bosan dan lain sebagainya. Sedangkan respon organisasi meliputi terjadinya penurunan produktivitas kerja, kurangnya kontribusi dalam bekerja dan lain sebagainya [5].

Kelelahan kerja dapat menimbulkan beberapa keadaan yaitu fungsi fisiologis motorik dan neural yang menurun, badan terasa kurang sehat sehingga semangat kerja menurun. Perasaan kelelahan cenderung meningkatkan terjadinya kecelakaan kerja, sehingga dapat merugikan diri sendiri maupun perusahaan karena adanya penurunan produktivitas kerja. Kelelahan kerja terbukti memberikan kontribusi lebih dari $60 \%$ dalam kejadian kecelakaan ditempat kerja [6].

Upaya yang dapat dilakukan untuk meningkatkan derajat kesehatan fisik dan psikologis petani karet adalah dengan dengan melakukan penyuluhan terkait stres kerja dan kelelahan kerja, agar petani mengerti terkait stres kerja. Serta cara mengajarkan manajemen stres melalui terapi relaksasi dan terapi otot progresif untuk menurunkan stres serta terapi lainnya.

\section{Metode Penelitian}

Desain penelitian ini adalah analitik observasional dengan pendekatan cross-sectional. Sampel yang digunakan sebanyak 78 petani karet di PTPN XII Kebun Renteng Kecamatan Ajung Kabupaten Jember dengan simple random sampling. Kriteria inklusi pada penelitian ini adalah petani yang dapat berbicara dengan baik serta bersedia menjadi responden. Sedangkan kriteria eksklusi pada penelitian ini adalah petani yang memiliki keterbatasan fisik, seperti tuli, bisu dan cacat fisik.

Instrumen dalam penelitian ini menggunakan pertanyaan tentang karakteristik responden, kuisioner stres kerja, dan kuisioner Fatigue Severity Scale (FSS). Instrumen stres kerja terdiri dari 10 item pertanyaan dengan skor 10 untuk terendah dan 50 untuk tertinggi. Instrumen Fatigue Severity Scale (FSS) terdiri dari 9 item pertanyaan dengan skala skor 9 untuk terendah dan 63 untuk tertinggi. Data dianalisis menggunakan SPSS. Data fatigue dan stres disajikan dalam bentuk frekuensi dan rerata setiap indikator. Hubungan fatigue dan stres diuji menggunakan uji statistik spearman dengan signifikansi 0,05 .

\section{Hasil Penelitian}

\section{Karakteristik responden}

Tabel 1. Karakteristik responden berdasarkan usia dan lama bekerja Petani Karet di PTPN XII Kebun Renteng Kecamatan Ajung KabupatenJember $2019(n=78)$

\begin{tabular}{ccc}
\hline Variabel & Median & Min-Max \\
\hline Usia (tahun) & 38,50 & $35-77$ \\
\hline Lama Bekerja (tahun) & 2,00 & $1-2$ \\
\hline
\end{tabular}

Sumber : Data primer peneliti, Juli 2019

Tabel 1 didapatkan hasil untuk nilai tengah usia petani karet adalah 39 tahun dengan usia termuda adalah usia 35 tahun sedangkan usia tertua adalah 77 tahun. Untuk nilai tengah lama bekerja petani adalah 2 sedangkan minimal bekerja 1 tahun dan maksimal bekerja 2 tahun.

Tabel 2. Karakteristik Petani Karet di PTPN XII Kebun Renteng Kecamatan Ajung KabupatenJember $2019(n=78)$

\begin{tabular}{lcc}
\hline \multicolumn{1}{c}{ Variabel } & $\begin{array}{c}\text { Jumlah } \\
(\mathrm{n})\end{array}$ & $\begin{array}{c}\text { Persentase } \\
(\%)\end{array}$ \\
\hline Jenis Kelamin & & \\
Laki-Laki & 50 & $64,1 \%$ \\
Perempuan & 28 & $35,9 \%$ \\
Total & $\underline{78}$ & $100 \%$ \\
\hline
\end{tabular}


Mulianigrum, et al, Hubungan Stres Kerja Dengan Kelelahan Kerja Petani Karet di PTPN XII Renteng....

\begin{tabular}{|c|c|c|}
\hline \multicolumn{2}{|c|}{ Status Pernikahan } & \\
\hline Menikah & 70 & $89,7 \%$ \\
\hline Belum Menikah & 3 & $3.8 \%$ \\
\hline Janda/Duda & 5 & $6,4 \%$ \\
\hline Total & 78 & $100 \%$ \\
\hline Tingkat Pendid & & \\
\hline Tidak Sekolah & 4 & $5,1 \%$ \\
\hline SD & 54 & $69,2 \%$ \\
\hline SMP & 18 & $23,1 \%$ \\
\hline SMA & 2 & $2,6 \%$ \\
\hline Total & 78 & $100 \%$ \\
\hline Keluhan Fisik & & \\
\hline Nyeri & 31 & $39,7 \%$ \\
\hline Pegal & 21 & $26,9 \%$ \\
\hline Flu & 7 & $9,0 \%$ \\
\hline Demam & 6 & $7,7 \%$ \\
\hline Pusing & 13 & $16,7 \%$ \\
\hline $\begin{array}{l}\text { Total } \\
\text { Sumber : Data p }\end{array}$ & liti, & $100 \%$ \\
\hline
\end{tabular}

Tabel 2 diperoleh hasil jumlah responden dengan jenis kelamin laki-laki petani karet lebih banyak dibandingkan dengan perempuan yaitu yaitu sebesar 50 orang $(64,1 \%)$. Status pernikahan yang paling banyak yaitu menikah sejumlah 70 orang $(89,7 \%)$. Tingkat pendidikan terakhir responden yang paling banyak yaitu pada tingkat SD yaitu sebanyak 54 orang $(69,2 \%)$. Keluhan fisik yang paling banyak dialami responden adalah nyeri yaitu berjumlah 31 orang $(39,7 \%)$.

\section{Gambaran Stres Kerja}

Tabel 3. Nilai Rerata Stres Kerja Pada Petani Karet di PTPN XII Kebun Renteng Kecamatan Ajung Kabupaten Jember $(n=78)$

\begin{tabular}{ccc}
\hline Variabel & Median & Min-Mak \\
\hline Stres Kerja & 38,00 & $24-43$ \\
\hline \multicolumn{3}{l}{ Sumber : Data primer peneliti, Juli 2019}
\end{tabular}

Berdasarkan pada tabel 3 diketahui bahwa nilai median stres kerja pada petani karet di PTPN XII Kebun Renteng Kecamatan Ajung Kabupaten Jember adalah 38 dengan nilai minimal 24 sedangkan nilai maksimal 43.

Tabel 4. Distribusi Nilai Stres Kerja Pada Petani Karet di PTPN XII Kebun Renteng Kecamatan Ajung Kabupaten Jember $(n=78)$

\begin{tabular}{ccc}
\hline Stres Kerja & N & Persentase (\%) \\
\hline Rendah & 30 & 38,5 \\
Tinggi & 48 & 61,5 \\
\hline
\end{tabular}

Sumber : Data Primer peneliti, Juli 2019

Tabel 4 menunjukkan bahwa sebanyak 30 petani karet $(38,5 \%)$ mengalami stres rendah dan sebanyak 48 petani karet $(61,5 \%)$ mengalami stres kerja tinggi.

\section{Gambaran Kelelahan Kerja}

Tabel 5. Nilai rerata kelelahan petani Ajuriy nadupater Jember $(n=10)$

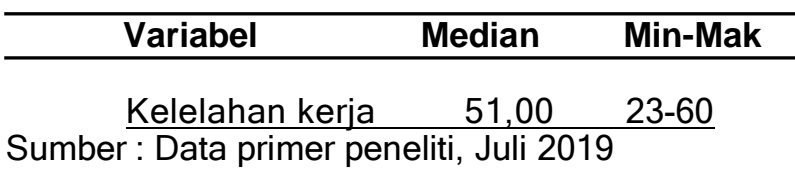

Dalam tabel 5 diketahui bahwa nilai median kelelahan kerja pada petani karet di PTPN XII Kebun Renteng Kecamatan Ajung Kabupaten Jember adalah 51 dengan nilai minimal 23 sedangkan nilai maksimal 60 .

Tabel 6. Distribusi Nilai Kelelahan Kerja Pada Petani Karet di PTPN XII Kebun Renteng Kecamatan Ajung Kabupaten Jember $(n=78)$

\begin{tabular}{|c|c|c|}
\hline Kelelahan Keria & $\mathbf{N}$ & Persentase (\%) \\
\hline Rendah & 32 & 41 \\
\hline Tinggi & 56 & 59 \\
\hline
\end{tabular}

Sumber : Data primer peneliti, Juli 2019

Berdasarkan tabel 6 diketahui bahwa sebanyak 32 petani karet $(41 \%)$ mengalami kelelahan kerja rendah dan sebanyak 56 petani karet (59\%) mengalami kelelahan kerja tinggi.

\section{Hubungan Stres Kerja dan Kelelahan Kerja} Tabel 7. Hasil Analisis Hubungan Stres Kerja dengan Kelelahan Kerja pada Petani Karet di PTPN XII Kebun Renteng Kecamatan Ajung Kabupaten Jember $(n=78)$

\begin{tabular}{ccc}
\hline \multicolumn{2}{c}{ Variabel } & Kelelahan Kerja \\
\hline Stres Kerja & $\mathrm{r}$ & 0,538 \\
& $p$ value & 0,000 \\
\hline
\end{tabular}

Sumber : data primer peneliti, Juli 2019

Berdasarkan tabel 7 diketahui bahwa hasil analisis hubungan stres kerja dan kelelahan kerja petani karet di PTPN XII Kebun Renteng

Ajung,Jember.

Menggunakan uji Spearman-rank dan didapatkan nilai $\rho$ value $<0,0,5$ korelasi $=0,538$,terdapat hubungan antara stres kerja dengan kelelahankerja 
Mulianigrum, et al, Hubungan Stres Kerja Dengan Kelelahan Kerja Petani Karet di PTPN XII Renteng....

memiliki hubungan positif atau searah, yakni jika petani mengalami stres kerja maka petani juga akan mengalami kelelahan kerja.

\section{Pembahasan}

\section{Karakteristik responden}

Petani karet mayoritas berjenis kelamin laki-laki $64,1 \%$, sejalan dengan penelitian yang dilakukan oleh Kallioniemi dkk (2016) menyatakan bahwa jumlah petani pemerah susu sapi mayoritas adalah laki-laki sebesar $56 \%$ [7]. Peran gender dari suatu wilayah akan berbeda dari peran gender lainnya sesuai dengan karakteristik wilayahnya [8]. Hal ini sama dengan lokasi PTPN XII Renteng yang berada pada dataran rendah dengan cara kerja yang lebih menggunakan kekuatan fisik petani, dimulai dari proses penyadapan yang dilakukan pada malam hari hingga mengumpulkan getah pada pagi hari. Sehingga pekerjaan tersebut lebih banyak dilakukan oleh laki-laki. Sebagian besar usia petani karet adalah $<30$ tahun dan sejalan dengan penelitian yang menunjukkan bahwa mayoritas pekerja berusia $\geq 30$ tahun yaitu sebesar $67,1 \%$

Pada usia produktif tubuh cenderung lebih mampu bekerja, cepat, kuat, ulet, dan teliti [9]. Usia produktif adalah usia memasuki tugas perkembangan usia produktif, dimana individu siap bekerja. Kelompok usia20-30 adalah usia yang sangat produktif karena fungsi tubuh masih baik dan kuat untuk bekerja. Bertambahnya usia seseorang akan diikuti perusakan jaringan tubuh yang menyebabkan turunnya kemampuan otot dan fungsi organ yang lain. Penurunan kemampuan melakukan aktivitas dan kemampuan kerja menjadi menurun disebabkan oleh penyusutan jaringan tubuh secara bertahap.

Penurunan fungsi fisiologis, neurologis, dan kemampuan fisik terjadi sesudah umur antara 30 40 tahun dengan irama yang berbeda untuk setiap orang. Semakin tua usia, pekerja cenderung mengalami kelelahan kerja [10]. Mayoritas petani karet telah menikah $89,7 \%$, sama dengan penelitian yang menyatakan bahwa pekerja di Indonesia mayoritas berstatus menikah sebesar $68,6 \%$ [10]. pernikahan mengarahkan para individu untuk memberikan prioritas kehidupan personal mereka lebih tinggi dibandingkan pada kehidupan kerja mereka. Ketika seseorang menikah, maka prioritas yang akan diberikan pada keluarga semakin besarseperti kewajiban untuk menafkahi keluarga [11]. Status pendidikan petani karet dalam penelitian mayoritas adalah SD $(69,2 \%)$, penelitian terdahulu menyatakan bahwa $76 \%$ karyawan mendapatkan posisi kerja yang sesuai dengan latar belakang pendidikan yang dimiliki dan ada terdapat sekitar $26 \%$ yang tidak sesuai dengan latar belakang pendidikan yang dimiliki [12].

Kinerja (prestasi kerja) adalah hasil kerja setelah kualitas dan kuantitas yang dicapai oleh seorang dalam melaksanakan tugasnya sesuai dengan tanggung jawab yang diberikan kepadanya [13]. Untuk lama kerja petani karet, mayoritas petani karet telah $>5$ tahun bekerja $(87,2 \%)$. Pekerjaan yang dilakukan terus menerus dengan jangka waktu yang panjang akan menyebabkan kejenuhan dan ketegangan sehingga mempercepat terjadinya kelelahan kerja [14]. Masa kerja erat kaitannya dengan kemampuan beradaptasi antara seorang pekerja dengan pekerjaan dan lingkungan kerjanya. Proses adaptasi dapat memberikan efek positif yaitu dapat menurunkan ketegangan dan peningkatan aktivitas atau performasi kerja, sedangkan efek negatifnya adalah batas ketahanan tubuh yang berlebihan akibat tekanan yang didapatkan pada proses kerja. Hal tersebut yang menjadi sebab timbulnya kelelahan yang membawa pada penurunan fungsi psikologi dan fisiologi [15].

Banyak petani yang mengeluh tentang fisiknya, didapatkan keluhan nyeri yang paling banyak yaitu $39,7 \%$. Penelitian yang dilakukan oleh Riyadina (2008) menyatakan bahwa ada beberapa keluhan yang dirasakan oleh pekerja yakni nyeri. Nyeri tubuh mucul karena akumulasi pembebanan pada tubuh dan tulang belakang akibat aktivitas seharihari yang dilakukan saat bekerja Faktor pekerjaan antara lain postur tubuh saat bekerja, frekuensi, durasi, gaya atau beban dan gerakan berulang [16].

\section{Gambaran Stres Kerja}

Hasil penelitian menunjukan bahwa didapatkan 30 petani $(38,5 \%)$ memiliki stres rendah sedangkan 48 petani $(61,5 \%)$ memiliki stres tinggi, yang berarti bahwa petani karet di PTPN XII Kebun Renteng Kecamatan Ajung Kabupaten Jember mengalami stres kerja tinggi. Sejalan dengan penelitian yang dilakukan terhadap 15 pekerja dan didapatkan hasil bahwa pekerja mengalami stres kerja ringan dengan persentase $6,67 \%$ atau sebanyak 1 orang, stres kerja sedang dengan persentase $60 \%$ atau sebanyak 9 orang, dan stres kerja berat dengan persentase $33,33 \%$ atau sebanyak 5 orang [17]. Stres kerja dapat berakibat positif (eustress) yang diperlukan untuk menghasilkan prestasi yang tinggi, namun pada umumnya stres kerja lebih banyak merugikan diri sendiri maupun tempat kerja [18]. 
Masalah stres kerja timbul saat seseorang harus melakukan tuntutan untuk efisien di dalam pekerjaan. Apabila petani mengalami stres kerja, hendaknya petani tersebut dapat melakukan teknik relaksasi dan distraksi berupa latihan tarik nafas dalam atau mendengarkan musik yang bisa membuat tubuh tenang dan mengurangi kadar stres yang dialami. Petani harus mengoptimalkan konsultasi kepada tenaga kesehatan, khususnya perawat untuk mendapat solusi dan terapi yang tepat untuk mengatasi stres kerja.

\section{Gambaran Kelelahan Kerja}

Hasil penelitian menunjukan bahwa sebanyak 32 petani $(41 \%)$ memiliki kelelahan kerja ringan dan 40 petani (59\%) memiliki kelelahan kerja tinggi yang berarti bahwa petani karet rmengalami kelelahan kerja tinggi. Sejalan dengan hasil penelitian yang mengatakan bahwa responden yang mengalami kelelahan kerja sedang disebabkan oleh waktu kerja dan waktu istirahat yang tidak sesuai.Responden dengan tingkat kelelahan kerja rendah masih mampu melakukan pekerjaannya sesuai target sedangkan responden dengan tingkat kelelahan kerja sedang tidak mampu melakukan pekerjaannya sesuai target [19].

Kelelahan kerja adalah salah satu permasalahan kesehatan dan keselamatan kerja yang dapat menjadi faktor risiko terjadinya kecelakaan pada saat bekerja. Kelelahan dapat disebabkan oleh beberapa faktor baik faktor internal maupun faktor eksternal. Faktor internal diantaranya usia, masa kerja, kualitas tidur, dan beban kerja, sedangkan faktor eksternal yaitu waktukerja dan iklim kerja yang tidak menentu [19]. Karena seseorang menggunakan sistem kerja seperti ini maka akan mempengaruhi ritme sikardian dan dapat mengakibatkan gangguan tidur hingga penyakit lainnya. Sesuai dengan data yang diperoleh, banyak petani yang mengeluh pusing dan susah tidur dikarenakan setiap hari bekerja pada malam hari.

\section{Hubungan Stres Kerja dan Kelelahan Kerja}

Hasil uji statistik Spearman's diperoleh $p$ value $0,000(\alpha \leq 0,05)$ artinya terdapat hubungan antara stres kerja dengan kelelahan kerja pada petani karet di PTPN XII Kebun Renteng Kecamatan Ajung Kabupaten Jember. Nilai kekuatan korelasi sedang atau $r$ value $=0,538$ artinya memiliki hubungan positif atau searah, yakni semakin tinggi stres kerja yang dialami maka petani akan mengalami kelelahan kerja. Petani yang mengalami stres akibat tekanan kerja yang tinggi disebabkan salah satunya yaitu kondisi iklim atau cuaca, faktor ekonomi, penyesuaian peraturan pemerintah, kekurangan tenaga kerja dan pengaruh perdagangan [20]. Dampak dari stres akibat kerja dapat menyebabkan reaksi emosional, perubahan kebiasaan atau mental dan perubahan fisiologis. Salah satu perubahan fisiologis yaitu kelelahan. Stres yang dialami seseorang dipengaruhi oleh sistem kerja saraf melalui stresor dari dalam maupun luar [21].

Kelelahan kerja menunjukkan perbedaan antara keadaan fisik tubuh dengan mental yang akan mengakibatkan penurunan pada daya kerja dan ketahanan tubuh untuk bekerja akan berkurang. Karena tuntutan yang harus dicapai maka petani harus tetap melakukan pekerjaannya dengan intens dan memenuhi tuntutan tersebut. Semua itu dapat menjadi faktor pemicu terjadinya kelelahan kerja [21]. Petani tersebut menunjukkan beberapa respon tubuh yang menandakan bahwa mereka sedang mengalami stres kerja dan kelelahan kerja. Adanya keluhan sakit kepala atau pusing akibat tekanan darah yang tinggi dan rendah, kurangnya semangat dalam bekerja, petani terlihat bermalasmalasan saat mengumpulkan getah karet, mudah tersinggung, raut wajah terlihat lelah dan meningkatnya absensi karena petani merasa sangat lelah. Semakin sering petani mengalami stres kerja maka semakin sering pula petani mengalami kelelahan kerja dan akan mengakibatkan munculnya dampak fisik maupun psikologis

\section{Simpulan dan Saran Simpulan}

Berdasarkan hasil peneitian dapat disimpulkan bahwa ada hubungan yang signifikan antara stres kerja dan kelelahan kerja dengan $p=0,000$. Korelasi sebesar 0,538 yang menunjukkan bahwa terdapat hubungan dengan keeratan yang sedang dan bersifat positif yaitu semakin tinggi stres kerja rendah maka semakin tinggi kelelahan kerjanya.

\section{Saran}

Petugas kesehatan khususnya perawat harus perawat dapat melakukan skrining dan pendidikan kesehatan mengenai stres kerja yang dapat menyebabkan kelelahan kerja. Pemberian pendidikan kesehatan terkait penatalaksanan manajemen stres dapat diberikan kepada petani, agar petani mampu mengatasi stres kerja yang dialami dan tidak menyebabkan kelelahan kerja. 
Mulianigrum, et al, Hubungan Stres Kerja Dengan Kelelahan Kerja Petani Karet di PTPN XII Renteng....

\section{Ucapan Terimakasih}

Peneliti menyampaikan terimakasih kepada responden penelitian dan PTPN XII Kebun Renteng Kecamatan Ajung Kabupaten Jember yang telah memberikan ijin dan bersedia menjadi responden penelitian sehingga penelitian ini bisa terselesaikan.

\section{Daftar Pustaka}

[1] Rodjak, Abdul. 2006. Manajemen Usaha Tani. Jilid II. Bandung: Pustaka Gratuna

[2] Perry, A, G., \& Potter, P.A. 2005. Buku ajar fundamental keperawatan: Konsep, proses dan praktik. (Ed 4). (Y. Asih, Terj.). Jakarta: EGC.

[3] Maghfiroh, Intan, dkk. 2017. Hubungan Stres Dan Motivasi Kerja Dengan Hasil Kerja Operator Jahit PO. Seventeen Glory Salatiga. Jurnal Kesehatan Masyarakat (e-Journal), 5(3): 278-285. [serial online] https://ejournal3.undip.ac.id/index.php/jkm/arti cle/viewFile/17237/16494 diakses pada 20 Februari 2019

[4] Lisdiana. 2014. Regulasi Kortisol Pada Kondisi Stres Dan Addiction. Biosaintifika 4 (1):18-26.

[5] Fadhillah, Luthfi M. 2010. Analisis Pengaruh Stres Kerja Terhadap Kepuasan Kerja Dengan Dukungan Sosial Sebagai Variabel Moderating (Studi Pada PT. Coca Cola Amatil Indonesia, Central Java). Semarang : Badan Penerbit Universitas Diponegoro.

[6] Setyawati, K. 2010. Selintas Tentang Kelelahan Kerja. Yogyakarta: Amara Books.

[7] Kallioniemi, M., Simola, A., Kaseva, J., Kymalainen, H. 2016. Stress And Burnout Among Finnish Dairy Farmers. [serial online] http://backup.scihub.tw/6198/7900cc8190b08a ec12a0a35f113d137a/kallioniemi2016.pdf diakses tanggal 12 Juli 2019

[8] Mulyaningsih, Asih., Hubeis, Aida V.S., Sadono, Dwi., Susanto, Djoko. 2018. Partisipasi Petani pada Usahatani Padi, Jagung, dan Kedelai Perspektif Gender [serial online]

http://jesl.journal.ipb.ac.id/index.php/jupe/articl e/viewFile/18546/14488 diakses tanggal 12 Juli 2019

[9] Mantra, Bagoes Ida.2004.Demografi Umum.Yogyakarta.Pustaka Pelajar

[10] Saputri, Widyanfri W. P. 2017. Gambaran Kejadian Burnout Berdasarkan Faktor Determinannya Pada Pekerja Gudang Dan Lapangan PT. Multi Terminal Indonesia. [serial online]

http://repository.uinjkt.ac.id/dspace/bitstream/1 23456789/35890/1/Widyanfri\%20Wira\%20Prat ama\%20Saputri-FKIK.pdf diakses tanggal 12 Juli 2019

[11] Kismono, Gugup. 2013. Manajemen Bisnis. Yogyakarta: BPFE

[12] Arisandra, Martha L. 2016. Pengaruh Tingkat Pendidikan, Keterampilan Kerja Dan Sikap Kerja Karyawan Terhadap Prestasi Kerja Karyawan Pt. Bpr Nusamba Brondong Lamongan. Jurnal Ekonomi Universitas Kadiri, Vol. 1, No. 2: 103-116 [serial online] https://www.researchgate.net/publication/3269 15357 Pengaruh Tingkat Pendidikan Ketera mpilan Kerja Dan Sikap Kerja Karyawan T erhadap Prestasi Kerja Karyawan Pt Bpr N usamba Brondong Lamongan diakses pada 25 Juli 2019

[13] Mangkunegara, Prabu. 2000. Manajemen Sumber Daya Manusia Perusahaan, Cetakan ke 2 PT. Remaja Rosda Karya, Bandung

[14] Paulina dan Salbiah. 2016. Faktor yang Berhubungan Dengan Kelelahan Pada Pekerja Di PT Kalimantan Steel. Jurnal Vokasi Kesehatan, (online), Vol. 2, No. 2, 377-384. [serial online] ejournal.poltekkespontianak.ac.id/index.php/J VK/article/download/50/57 diakses tanggal 14 Juli 2019

[15] Atiqoh, Januar., Wahyuni, Ida., Lestantyo, Daru. 2014. Faktor-Faktor yang Berhubungan dengan Kelelahan Kerja pada Pekerja Konveksi Bagian Penjahitan di CV. Aneka Garment Gunungpati Semarang

[16] Kambodji, Joyce., 2002. Pengaruh Intensitas Nyeri Terhadap Keterbatasan Fungsional Aktivitas Sehari-hari Penderita Nyeri Punggung Bawah Kronis. Universitas Gadjah Mada. Pendidikan Dokter Spesialis Saraf.

[17] Widyastuti , A.D. 2017. Hubungan Stres Kerja Dengan Kelelahan Kerja Pada Pekerja Area Workshop Konstruksi Box Truck. The Indonesian Journal Of Occupational Safety And Health, Vol. 6, No. 2: 216-224. [serial online] $\quad$ https://ejournal.unair.ac.id/IJOSH/article/view/4512 diakses pada 10 Februari 2019

[18] Munandar, Ashar. S (2008). Psikologi Industri dan Organisasi. Penerbit Universitas Indonesia (UI-Press)

[19] Verawati, Lince. 2016. Hubungan Tingkat Kelelahan Subjektif Dengan Produktivitas Pada Tenaga Kerja Bagian Pengemasan Di CV Sumber Barokah. The Indonesian Journal of Occupational Safety and Health, Vol. 5, No. 
Mulianigrum, et al, Hubungan Stres Kerja Dengan Kelelahan Kerja Petani Karet di PTPN XII Renteng....

1 Jan-Jun 2016: 51-60 [serial online] https://ejournal.unair.ac.id//JOSH/article/view/3799/25 71 diakses pada tanggal 14 Juli 2019

[20] Huat Bin (Andy), A. 2010. Occupational Stres Among the New Zealand Farmers- A Review. New Zealand: Auckland University of Technology.

[21] Tarwaka. 2015. Ergonomi Industri - Dasardasar Pengetahuan Ergonomi dan Aplikasi di Tempat Kerja. Surakarta: Harapan Press Solo. 